\title{
EMPRESAS INOVADORAS E FUNDOS DE VENTURE CAPITAL: O OLHAR DOS INVESTIDORES
}

Livia Ribeiro Borges De Faria ${ }^{1}$

Irene Ciccarino ${ }^{2}$

Ana Beatriz Gomes De Mello Moraes ${ }^{3}$

\footnotetext{
${ }^{1}$ Administração / Faculdade / IBMEC

${ }^{2}$ Pontifícia Universidade Católica do Rio de Janeiro (PUC-Rio)

${ }^{3}$ IBMEC
} 


\section{EMPRESAS INOVADORAS E FUNDOS DE VENTURE CAPITAL: O OLHAR DOS INVESTIDORES}

Resumo: Através dos investimentos de venture capital [VC], pequenas e médias empresas passam a dispor de recursos adequados para financiar o seu crescimento, garantindo a sustentabilidade futura do negócio. Para financiar novos negócios, os gestores de VC desenvolvem metodologias próprias para avaliarem os candidatos. É nesse contexto que se insere essa pesquisa. Busca-se investigar as características percebidas pelos gestores de VC quando selecionam empresas inovadoras para investir. Pretende-se identificar as percepções e metodologias empregadas no processo de escolha dos negócios que receberão aporte de VC por meio do BNDES Participações S.A, buscando compreender como os gestores de VC atuam no sentido de incentivar o processo inovador. A percepção desses gestores em relação à inovação será comparada com o que postula a literatura sobre as características essenciais das empresas inovadoras. Os resultados indicam que há uma convergência entre a opinião dos gestores de VC entrevistados e a literatura que trata do assunto.

Palavras-chave: Inovação. Venture Capital. Capital de Risco. Investimento em Inovação

\section{Introdução}

A atividade de inovar pode ser bastante custosa, principalmente para as pequenas e médias empresas. Estas, geralmente, possuem fluxo de caixa limitado e não conseguem se financiar. Tampouco conseguem capital externo facilmente, dado o risco do negócio e a falta de garantias. Nessa esteira, o capital de risco, notadamente conhecido como venture capital ("VC"), pode resolver esse problema, financiando pequenas e médias empresas inovadoras.

O financiamento pode ser um fator determinante para a inovação em pequenas e médias empresas [PMEs], que, costumeiramente, carecem de recursos para conduzir projetos desse cunho e enfrentam dificuldades para obter financiamento externo. No sistema financeiro, a atividade de VC se apresenta como uma alternativa viável ao financiamento das PMEs, visto que os gestores são agentes hábeis para mitigar os riscos desses investimentos que, normalmente, não possuem histórico financeiro ou ativos que possam ser dados em garantia (RIBEIRO, 2005).

Importa mencionar que a dificuldade de angariar financiamento junto a instituições financeiras ou investidores privados já foi apontada como uma das maiores dificuldades ao desenvolvimento das empresas de base tecnológica no Brasil. Segundo o relatório do SEBRAE (2001), o risco associado às fases iniciais de desenvolvimento das tecnologias e produtos adotados por essas empresas é o fator que inibe a concessão de crédito por parte das instituições financeiras que lidam com financiamentos tradicionais.
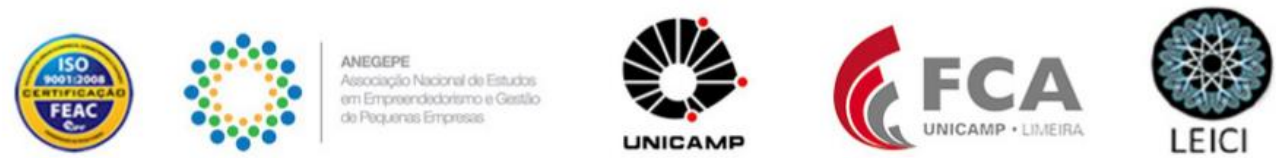
Assim sendo, os veículos de investimento de VC representam uma importante fonte de financiamento para o desenvolvimento de empresas inovadoras no país, pois oferecem recursos com um horizonte de longo prazo em condições mais atraentes do que um empréstimo bancário convencional. Isso ocorre porque dividem o risco com o empreendedor, não exigindo garantias.

Por reconhecer o papel dos veículos de investimento de $\mathrm{VC}$, este artigo busca responder à questão: quais as características que os gestores de $\mathrm{VC}$ consideram cruciais para verificar o potencial de inovação das empresas a serem investidas? Busca-se aprofundar o conhecimento em três frentes: (1) nessa relação comercial, por meio da evidência dos aspectos considerados essenciais na escolha de investimentos; (2) na identificação das ferramentas mais utilizadas para avaliar o potencial de inovação das empresas a serem investidas; e (3) das ferramentas utilizadas pelos gestores para estimular o potencial inovador das empresas.

Para investigar o fenômeno da inovação no contexto dos investimentos em $\mathrm{VC}$, o estudo procura explorar a experiência e identificar a metodologia usada por gestores de fundos para de VC. Ao identificar as características observadas pelos que concedem o investimento, sinaliza-se o que de fato agiliza o processo de financiamento da inovação, e torna-se possível compreender quais atividades inovadoras das empresas são efetivamente observadas e estimuladas. Dessa forma, contribui-se tanto para teoria quanto para a prática. As implicações teóricas são concernentes às informações detalhadas do contexto nacional por apresentar um estudo de caso do braço de participações do Banco Nacional de Desenvolvimento Econômico e Social [BNDES], a BNDES Participações S.A. A percepção desses gestores em relação à inovação também será comparada com o que postula a literatura sobre as características essenciais das empresas inovadoras, ampliando a contribuição teórica deste trabalho. As implicações práticas atingem principalmente as pequenas e médias empresas que desejam financiamento para iniciativas de inovação, pois terão acesso ao detalhamento do que esses gestores levam em consideração na seleção de seus investimentos.

O trabalho está organizado da seguinte forma: após esta introdução, o referencial teórico versa sobre a definição de $\mathrm{VC}$, o conceito de inovação, os indicadores de inovação e as estratégias de apoio à inovação. Na sequência, é descrita a metodologia aplicada ao estudo e, enfim, são apresentados e discutidos os resultados do estudo.

\section{Referencial Teórico}

\subsection{Venture Captal [VC]}

Os gestores dos fundos de VC podem contribuir de várias maneiras para o crescimento de empresas, desde recursos financeiros até com o aprimoramento da gestão. Segundo Ribeiro (2005), os gestores também podem ajudar as empresas investidas a crescer por meio da gestão do dia a dia das operações, passando desde a instalação de estruturas modernas de governança corporativa até ao compartilhamento da rede de contato dos gestores dos fundos.
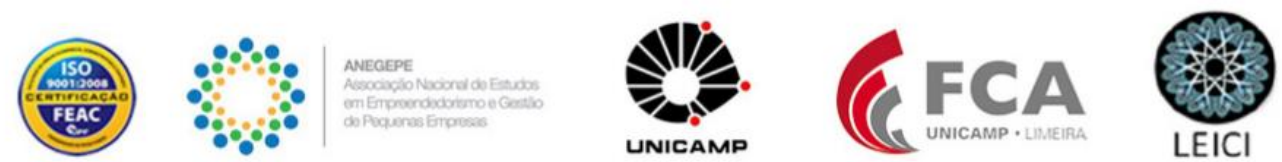
Atualmente, os veículos de VC exercem uma função de grande relevância para o fomento à inovação. Kortum e Lerner (2000) investigaram a relação entre investimentos em VC e o depósito de patentes. Os autores estudaram 20 empresas americanas entre 1965 e 1992 e concluíram que o investimento por meio de veículos de VC está associado a setores que, usualmente, possuem mais produção de patentes. Os autores estimaram que os investimentos por meio de VC foram responsáveis por $8 \%$ das inovações industriais entre os anos de 19831992.

Bogliacino e Lucchese (2011) realizaram um estudo sobre os impactos dos investimentos de $\mathrm{VC}$ em 23 países europeus e demonstraram que os países que mais se destacam em investimentos em pesquisa e desenvolvimento são os que mais investem por meio de VC. Dessa forma, os autores concluíram que quanto maior o potencial tecnológico do país, maior o apelo para investimentos de $\mathrm{VC}$, tanto por parte da demanda, quanto por parte da oferta.

Arvanitis e Stucki (2014) identificaram os efeitos diretos dos investimentos de VC nas start-ups suíças e concluíram que as empresas que já haviam demonstrado capacidade de inovação prévia ao recebimento dos investimentos apresentaram maior atividade de inovação posteriormente. Nesse sentido, os autores sugerem que os investidores de VC selecionam empresas que já possuem um potencial inovador para investirem.

Para poderem financiar as empresas, os gestores de VC utilizam práticas sofisticadas de seleção, governança e monitoramento (SAHLMAN, 1990). Geralmente, não há um modelo formal de seleção definido, existem algumas questões centrais, tais como equipe, oportunidade de mercado e a proposição de valor/produto para a solução. Além disso, a diferenciação tecnológica ou a diferenciação do modelo de negócios também são observadas, visto que podem gerar uma vantagem competitiva.

Segundo Rieche e Santos (2006), outro determinante importante do sucesso é a indústria setor. Se a indústria for bem escolhida - mesmo que a equipe ou a execução não seja tão boa -, as empresas crescerão porque estão em ambiente próspero ou de expansão. Ainda, segundo os autores, a equipe é outro fator crítico de sucesso. Os autores defendem que devem ser analisadas as biografias do empreendedor e de sua equipe, em especial suas realizações profissionais, seu histórico e sua rede de relacionamento "networking", a fim de avaliar a possibilidade de estabelecer parcerias.

Segundo Engel (2011), os gestores de fundos de VC são conhecidos por investirem em empresas que tragam novas tecnologias ao mercado, contudo, quando perguntados, os gestores afirmam que investem em times e setores. Desse modo os investimentos de VC são fontes de financiamento complexas, porém acessíveis às pequenas e médias empresas, oferecendo prazos e condições mais atraentes do que um empréstimo bancário convencional.

\subsection{Inovação como processo e a empresa inovadora}

O conceito de inovação é encontrado em diversas fontes. O Manual de Oslo, criado pela Organização de Cooperação para o Desenvolvimento Econômico [OECD], descreve que

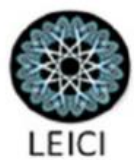


uma inovação é a implementação de um produto, seja ele bem ou serviço, novo ou significativamente aperfeiçoado, podendo também ser um processo, ou um novo método organizacional nas práticas de negócios, na organização do local de trabalho ou nas relações com o mercado (OECD, 2004). A inovação é vista como um processo contínuo, cumulativo, que envolve não só inovação radical e incremental, mas também a difusão, absorção e utilização de inovação (LUNDVALL, 2005). Teece, Pisano e Shuen (1997) explicam que o processo de inovação depende da trajetória da firma e dos conhecimentos que ela acumulou em sua história. Os autores afirmam que esse processo de aprendizado demanda tempo, restringindo as possibilidades de expansão. Por outro lado, essa acumulação de conhecimentos serve como mecanismo interno que induz ao crescimento. Nesse sentido, diferentes arranjos organizacionais adaptam-se mais ou menos aos diferentes tipos de ambientes competitivos e de inovação. A busca da organização é pela melhor combinação possível entre as características organizacionais já existentes e o tipo de inovação a ser implantado.

O Manual de Oslo (2004) define uma empresa como inovadora aquela que implementou ao menos uma inovação. No entanto, o próprio manual possibilita outras abordagens quando conceitua empresa ativamente inovadora como sendo a empresa que realizou atividades de inovação no período que estava sendo analisada.

O processo de introdução de uma inovação não é trivial, pois encontra frequentemente muitas dificuldade, como por exemplo, a atividade empresarial e as fontes de financiamento (BURLAMAQUI e PROENÇA, 2003). Ainda, segundo os autores, a atividade de inovação está permanentemente diante de dois tipos de barreiras: a primeira representada pela incerteza do futuro, na medida em que o sucesso ou fracasso de uma inovação não tem como ser garantido; e a segunda, relacionada com o peso do passado, que está na origem dos hábitos e rotinas empresariais, durabilidade do seu capital fixo e especificidade de seus ativos, todos potencialmente ameaçados pelas inovações. Assim, os autores afirmam que a conjugação entre a incerteza sobre o futuro e o peso do passado está no centro das decisões estratégicas sobre inovar.

"A capacidade de inovação de uma empresa pode ser compreendida como o seu potencial para gerar resultados inovadores. Este potencial depende de uma inter-relação sinérgica da cultura da empresa, dos processos internos e do ambiente externo" (NEELY e HII, 1999). A capacidade de inovação de uma empresa pode ser determinada por características como habilidade dos colaboradores, ou seja, os pesquisadores, os engenheiros e até mesmo a equipe de vendas que consegue compreender as novas tecnologias a serem vendidas; introdução de mudanças na estrutura organizacional; adoção de técnicas avançadas de gestão e formação de alianças estratégicas com parceiros (OECD, 2004).

Papaconstantinou (1997) pressupõe que a capacidade de inovar depende de alguns fatores, os quais o autor destaca como sendo os esforços para criar novos produtos, avanço nos processos de produção e capacidade para aprender.

Penrose (1959) explicou a firma como uma organização que reúne habilidades e conhecimentos e que, sua capacidade de inovar dependia exatamente da forma como a firma

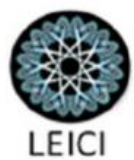


explorava essas habilidades e conhecimentos. A autora explica que os recursos produtivos, apesar de importantes, são um conjunto de serviços e que a forma como serão utilizados é que definirá a vantagem competitiva de uma firma sobre a outra. Assim sendo, a autora defende que a base tecnológica e o "espírito empreendedor" existem em cada firma, de forma única e distinta. Em seu trabalho, foi proposta uma análise da firma centrada nas suas capacitações internas. A função econômica primária da firma é fazer uso de recursos produtivos para fornecer mercadorias e serviços para a economia de acordo com planos desenvolvidos e executados dentro da firma (PENROSE, 1959).

Tidd, Bessant e Pavit (1997) caracterizam as empresas inovadoras como uma série de componentes integrados que, juntos, propiciam um ambiente para a criação da inovação. Os autores listam dez componentes que se interligam internamente para atingir os resultados esperados: liderança, estrutura apropriada, indivíduos, equipe, desenvolvimento individual, comunicação, envolvimento com inovação, foco no cliente, ambiente criativo e aprendizagem organizacional. Percebe-se que os componentes propostos tanto por Tidd, Bessant e Pavit (1997) e Rothwell (1994) contemplam as mais variadas esferas organizacionais e englobam pessoas, estrutura e clientes, ou seja, a inovação está diretamente relacionada à estrutura organizacional e a sua estratégia.

Segundo Metcalfe (2004), para compreender a natureza capitalista contemporânea, é necessário situar a questão do empreendedor no centro da análise, pois o empreendedor é o agente crucial, cujo papel é de gerar novos conhecimentos econômicos. A inovação não é gerada apenas por resultados de pesquisa e desenvolvimento. As práticas gerenciais antecedem e, em princípio, podem contribuir para a capacidade de inovação na empresa. A inovação é também de natureza empresarial e não simplesmente de natureza tecnológica (CUNHA, 2005).

Santos, Neto e Moura (2010) realizaram uma pesquisa com empresas brasileiras para verificar a existência de determinadas características nos gestores de empresas inovadoras. Os autores utilizaram as características dos estudos de Papadakis e Bourantas (1998) que relacionam cinco características de personalidades dos gestores que influenciam a tomada de decisão estratégica nas empresas. O estudo de Santos, Neto e Moura (2010) verificou que as características de personalidade descritas por Papadakis e Bourantas estão presentes nos gestores e são importantes no processo de manutenção, crescimento e inovação das organizações

Reconhecer as definições e os elementos que caracterizam uma empresa inovadora são essenciais para verificação da sua incorporação na prática de VC analisada por meio dos gestores entrevistados neste artigo. Outro elemento importante é a compreensão dos indicadores de inovação postulados na literatura para verificação de seu emprego nas práticas analisadas.

\subsection{Indicadores de inovação}

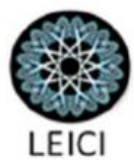


Atualmente, existe uma quantidade significativa de indicadores que servem para descrever o processo de inovação. Segundo Furtado e Queiroz (2007), os indicadores de insumo jogam o foco nos esforços realizados pelas empresas em pesquisa e desenvolvimento. A intensidade tecnológica ou de P\&D é o indicador mais usado para medir o esforço das empresas em pesquisa e desenvolvimento, e é calculado através da razão entre o gasto de $\mathrm{P} \& \mathrm{D}$ de uma empresa e as suas vendas ou valor adicionado. Ainda, segundo os autores, existem os indicadores de produtos, sendo o mais comum a patente de invenção, seja o seu depósito, ou seja, o seu registro, que ocorre vários anos depois.

A OECD, através do Manual de Oslo (2004), contribui para instituir indicadores que mensuram o nível de inovação nas empresas. O Manual indica quais elementos podem ser mensurados e forma uma estrutura para mensurar a inovação através de elementos da organização, das relações de demanda sob a ótica mercadológica e da difusão de novas tecnologias.

O Manual propõe a utilização da seguinte base de indicadores para avaliar o processo de inovação nas empresas: gastos com inovação, retorno de vendas com a inovação, redução de gastos com a inovação, criação de patentes, inovação no ciclo de vida dos produtos, inovação no produto, inovação no processo e inovação organizacional. A estrutura considera também as interações da empresa com outras empresas, com instituições de pesquisa e com a sociedade. A taxa de inovação é considerada o mais importante indicador derivado das pesquisas de inovação. Esse indicador mede o número relativo de empresas que introduziram pelo menos uma inovação tecnológica em um determinado período, em geral de três anos, sobre o conjunto total de empresas. Ainda na esfera do Manual, há o indicador de medição do impacto econômico da inovação pela participação da inovação nas vendas totais da empresa.

O IBGE (2013), através da pesquisa PINTEC, utiliza a taxa de inovação para avaliar a taxa de inovação dos setores. Nesse caso, a taxa de inovação é o resultado do número de empresas que responderam positivamente a questões sobre introdução de inovação, dividido pelo número total de empresas entrevistadas. O resultado é apresentado em forma percentual.

$\mathrm{O}$ reconhecimento dos elementos e dos indicadores deve ser colocado em prática por meio de uma estratégia de inovação. Tal elemento é um diferencial de planejamento e ajuda as empresa a concretizarem seus objetivos (KAPLAN e NORTON, 2004).

Fiates (2014) propõe estratégias para promover um processo sustentável de desenvolvimento e consolidação das empresas inovadoras de forma a transformá-las em empreendimentos bem-sucedidos. $\mathrm{O}$ autor destaca que, para isso acontecer, é importante o desenvolvimento de um conjunto de competências que muitas vezes estão presentes nos empreendedores do negócio ou que são adquiridas ao longo do processo de forma natural. Entretanto, também é possível, e cada vez mais frequente, o suporte a esses empreendimentos para que o processo de crescimento seja mais acelerado. $\mathrm{O}$ autor complementa que o foco dos sistemas de apoio à inovação está orientado para articular quatro grandes tipos de recursos fundamentais para o desempenho e competitividade de um empreendimento inovador: tecnologia, mercado, talentos e capital.
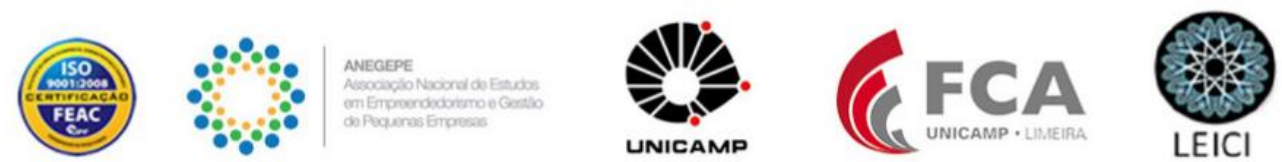
Especificamente em relação ao apoio dos gestores de VC, Fiates (2014) destaca que é esperada uma evolução mais significativa na medida em que se aportam recursos financeiros aliados ao conhecimento e às experiências por parte das entidades gestoras. Vogel (2012) apud Fiates (2014) segue na mesma direção, destacando que, para criar um ecossistema de empreendedorismo saudável e competitivo, é fundamental a presença de capital humano, capital financeiro e redes de acesso a mercado.

\section{Metodologia}

A pesquisa de cunho qualitativo adotou como método o Estudo de Caso no intuito de prover uma análise descritiva do processo de investimento por meio VC em empresas inovadoras (EISENHARDT, 1989). Este estudo busca aprofundar os conhecimentos compilados no referencial teórico gerando uma síntese que norteará a conclusão por meio da comparação com o material primário levantado por meio de entrevistas em profundidade semiestruturadas (REMENY et al,1998; EISENHARDT, 1989).

O critério de seleção dos casos baseou-se nos atributos do grupo de interesse.Foram realizadas entrevistas com questionário semiestruturado, com os gestores de fundos de VC que investem em empresas emergentes e inovadoras.

Os gestores escolhidos foram aqueles que gerem fundos de VC nos quais o BNDES, através do seu braço de participações, a BNDES Participações S.A. - BNDESPAR é quotista.

O objetivo das entrevistas foi o de levantar e interpretar as percepções e metodologias empregadas no processo de escolha da empresa a receber o aporte, bem como entender o modelo de atuação desses gestores no que tange o desenvolvimento das capacidades percebidas de forma a incentivar o processo inovador. As entrevistas aconteceram presencialmente nos meses de julho e agosto de 2015 com uma duração média de 3 horas cada, tendo sido gravadas, transcritas e posteriormente analisadas (DENZIN e LINCOLN, 2011).

As entrevistas foram realizadas com cinco gestores de $\mathrm{VC}$ que gerem fundos investidos pela BNDESPAR e cujo foco de investimento era empresas inovadoras nos setores que atuam. A investigação foi desenvolvida tomando por base questões norteadoras em torno do tema central: quais as características que os gestores de VC consideram cruciais para verificar o potencial de inovação das empresas a serem investidas? Dessa forma, foi formulada uma indagação inicial que deu o direcionamento para a pesquisa, no qual o estudo está focado, e posteriormente, criou-se um rol de questões que têm conexão com o objeto a ser desvendado. Também é necessário destacar que novas questões surgiram ao longo das entrevistas, tendo em vista a exploração de elementos que emergiam na fala dos entrevistados. O Quadro 1 demonstra a relação entre os objetivos de pesquisa e as questões empregadas nas entrevistas.

Quadro 1 - Relação entre objetivos específicos e questões norteadoras

\begin{tabular}{|l|l|}
\hline Objetivos Específicos & Questões Norteadoras \\
\hline
\end{tabular}




\begin{tabular}{|c|c|}
\hline $\begin{array}{l}\text { Verificar que aspectos são } \\
\text { considerados essenciais na } \\
\text { escolha do investimento }\end{array}$ & $\begin{array}{l}\text { Quais características são essenciais para a empresa ser investida? } \\
\text { Quais as habilidades devem ser observadas na equipe? } \\
\text { É importante o desenvolvimento de pelo menos uma inovação? } \\
\text { Há uma estrutura organizacional ideal? } \\
\text { Em relação à cultura organizacional, o que é observado? } \\
\text { Quais características importantes o empreendedor deve ter? } \\
\text { O foco no cliente é um ponto considerado na análise da empresa? }\end{array}$ \\
\hline $\begin{array}{l}\text { Verificar quais as } \\
\text { ferramentas utilizadas para } \\
\text { avaliar o potencial de } \\
\quad \text { inovação }\end{array}$ & $\begin{array}{l}\text { Quais ferramentas são utilizadas para avaliar o potencial de } \\
\text { inovação? } \\
\text { Vocês avaliam a intensidade tecnológica/P\&D? } \\
\text { O número de patentes é importante na avaliação da empresa? } \\
\text { Vocês analisam a taxa de inovação de setor? }\end{array}$ \\
\hline $\begin{array}{l}\text { Verificar quais ferramentas } \\
\text { são utilizadas para } \\
\text { estimular o potencial } \\
\text { inovador. }\end{array}$ & $\begin{array}{l}\text { Como o Gestor estimula o potencial inovador das empresas? } \\
\text { Qual o papel do financiamento no estímulo à inovação? } \\
\text { Em termos de gestão, qual a colaboração que pode ser dada nesse } \\
\text { aspecto? } \\
\text { Como a rede de contatos que vocês possuem ajuda a empresa? }\end{array}$ \\
\hline
\end{tabular}

Fonte: Quadro elaborado pelas autoras a partir da fundamentação teórica

Importa retomar aqui o objetivo deste trabalho, que é realizar uma pesquisa descritiva com o intuito de relatar e compreender as percepções da população estudada em relação às empresas. A pesquisa em questão busca levantar as características, conforme a percepção dos entrevistados, que as empresas devem possuir para serem consideradas inovadoras. Dito isto, o estudo não pretende indicar todas as características inerentes às empresas consideradas inovadoras. A metodologia da pesquisa foi configurada conforme as etapas a seguir: 1) Seleção da amostra de gestores; 2) Definição do roteiro da entrevista; 3) Realização e documentação das entrevistas; 4) Análise dos dados levantados; 5) Síntese das descobertas e reflexões.

Para fins desse trabalho, foram criadas três dimensões para entender a percepção dos gestores de VC sobre as empresas analisadas: 1) quais aspectos essenciais devem ser observados para que a empresa esteja apta a receber o investimento; 2) quais as ferramentas utilizadas para selecionar as empresas; e 3) quais os estímulos são dados às empresas para acelerar o processo inovador. Essas dimensões atendem aos objetivos de pesquisa descritos previamente. A Quadro 2 ilustra a relação entre essas dimensões e as características identificadas na revisão da literatura.

Quadro 2 - Aspectos Inovadores, Ferramentas de Avaliação e Estímulos para Inovar

\begin{tabular}{|c|l|l|}
\hline Dimensões & Característica & Autores \\
\hline \multirow{4}{*}{$\begin{array}{c}\text { Características } \\
\text { das empresas } \\
\text { inovadoras }\end{array}$} & $\begin{array}{l}\text { Equipe com } \\
\text { habilidades para inovar }\end{array}$ & $\begin{array}{l}\text { (CUNHA, 2005), (ENGEL, 2011), (OECD, 2004), } \\
\text { (ROTHWELL, 1994), (TIDD, BESSANT e PAVIT, } \\
\text { 1997) }\end{array}$ \\
\cline { 2 - 3 } & $\begin{array}{l}\text { Desenvolvimento de } \\
\text { pelo menos uma } \\
\text { inovação }\end{array}$ & (OECD, 2004) \\
\cline { 2 - 3 } & Estrutura & (ROTHWELL, 1994), (TIDD, BESSANT e PAVIT, \\
\hline
\end{tabular}




\begin{tabular}{|c|l|l|}
\hline \multirow{5}{*}{$\begin{array}{l}\text { organizacional } \\
\text { adequada }\end{array}$} & 1997) \\
\cline { 2 - 3 } & $\begin{array}{l}\text { Empreendedor } \\
\text { inovador }\end{array}$ & $\begin{array}{l}\text { (CUNHA, 2005), (SANTOS, NETO e MOURA, } \\
\text { 2010), (PAPADAKIS e BOURANTAS, 1998) }\end{array}$ \\
\cline { 2 - 3 } & Foco no cliente & $\begin{array}{l}\text { (ROTHWELL, 1994), (TIDD, BESSANT e PAVIT, } \\
\text { 1997) }\end{array}$ \\
\cline { 2 - 3 } & $\begin{array}{l}\text { Cultura Organizacional } \\
\text { com foco em inovar }\end{array}$ & $\begin{array}{l}\text { (ROTHWELL, 1994), (TIDD, BESSANT e PAVIT, } \\
\text { 1997) }\end{array}$ \\
\hline \multirow{3}{*}{$\begin{array}{c}\text { Avaliação do } \\
\text { potencial de } \\
\text { inovação }\end{array}$} & $\begin{array}{l}\text { A intensidade } \\
\text { tecnológica ou de P\&D }\end{array}$ & (FURTADO e QUEIROZ, 2007) \\
\cline { 2 - 3 } & Número de Patentes & $\begin{array}{l}\text { (FURTADO e QUEIROZ, 2007), (KORTUM e } \\
\text { LERNER, 2000) }\end{array}$ \\
\cline { 2 - 3 } & Taxa de inovação & (OECD, 2004), (IBGE, 2013) \\
\hline \multirow{2}{*}{$\begin{array}{c}\text { Estímulo à } \\
\text { inovação }\end{array}$} & Financiamento & $\begin{array}{l}\text { (RIBEIRO, 2005), (RAPINI, 2009), (ANSELMO e } \\
\text { GARCEZ, 2005) }\end{array}$ \\
\cline { 2 - 3 } & Gestão & (RIBEIRO, 2005) \\
\cline { 2 - 3 } & Rede de Contatos & (RIBEIRO, 2005), (ANSELMO e GARCEZ, 2005) \\
\hline
\end{tabular}

Fonte: Quadro elaborado pelas autoras a partir da fundamentação teórica

\section{Análise das Entrevistas}

A análise dos dados foi realizada por meio da interpretação das entrevistas coletadas. Para o acompanhamento dos dados, foi utilizada a técnica denominada análise de conteúdo. Depois de realizado o tratamento dos resultados, foi estabelecida a correspondência entre o nível empírico e o teórico (FRANCO, 2003).

Dentro das dimensões, as respostas foram categorizadas conforme as questões norteadoras pré-definidas, seguindo o método de classificação à priori (BARDIN, 1977). Uma vantagem desse tipo de categorização é a comodidade de poder classificar diretamente as unidades de análises dentro das categorias propostas. Para evitar que novos conteúdos não fossem abrangidos dentre as categorias propostas, criou-se uma categoria "outros" dentro de cada característica.

Em seguida, foi realizada a validação dos dados através da triangulação com a teoria, por meio dos elementos destacados na Tabela 2 a fim de encontrar validade intrínseca pelo embasamento de cada uma delas. Para ilustrar as análises das questões foram acrescentadas citações literais dos entrevistados (TAROZZI, 2008).

A seguir as dimensões descritas do Quadro 2 serão apresentadas de acordo com a comparação das características teóricos com os elementos que emergiram das entrevistas.

\subsection{Características das empresas inovadoras}

Nos relatos levantados na pesquisa, nota-se uma forte predominância da referência ao foco no cliente como característica predominante de empresas que inovam. Todos os

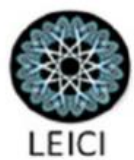


entrevistados mencionaram que é importante a empresa pensar na necessidade do cliente e almejar algum produto que, de fato, vai impactar em um mercado, e "não fazer a inovação pela inovação, para ser uma tese acadêmica, mas para ser algo que de fato vai impactar em um negócio, em um produto" (Gestor 1).

O Gestor 3, inclusive, mencionou que discute a tecnologia da empresa que está sendo avaliada junto aos seus potenciais clientes para ajudá-lo na tomada de decisão:

\begin{abstract}
"Boa parte da avaliação tecnológica não é feita por cientistas ou experts, a maior parte da avaliação tecnológica é feita pelos clientes, com os clientes, e com os potenciais clientes. Isso significa que não adianta a inovação ser muito de ruptura, muito impactante do ponto de vista tecnológico, e não ser muito bem avaliada pelo cliente, e pelo potencial cliente" (Gestor 3).
\end{abstract}

O Gestor 1 complementa o foco no cliente expondo que o produto deve ser singular e diferente do que há no mercado e, portanto, afirma que é importante "identificar quem são os concorrentes para aquela determinada tecnologia, quais são as características desses concorrentes, o que eles têm de vantagem e de desvantagem, avaliar o preço, a qualidade, a autonomia e as questões técnicas" (Gestor 1).

A equipe surge como ponto primordial na avaliação dos gestores. Sem exceção, todos afirmaram que a competência técnica da equipe é muito importante para a capacidade de inovar das empresas. Todos os entrevistados afirmaram avaliar a equipe em geral, porém em especial, o empreendedor. O conhecimento técnico é mencionado por todos como essencial no time de uma empresa que inova. O Gestor 1 complementa dizendo que deve haver pessoas realmente com vocação para inovar, com a capacidade de análise e formação acadêmica.

O Gestor 4 explica que em seu processo decisório, ele divide a avaliação em dimensões e, dentro de cada dimensão, são atribuídos notas e pesos para os itens avaliados. Na dimensão equipe são pontuados, dentre outras coisas, a experiência da equipe e seu poder de execução. Também são pontuados o conhecimento acadêmico, o conhecimento de mercado e a inserção dessa equipe no ecossistema de inovação, seja via centros de pesquisa, universidades etc.

No tocante ao empreendedor, as características observadas são principalmente as relacionadas com a capacidade de investir em inovações que possam ser comercializadas. É importante que o empreendedor tenha "o objetivo específico de desenvolver um determinado produto, o estado da arte, em um preço competitivo" (Gestor 1):

"Uma habilidade muito dificil de achar nesse mundo de pesquisa e desenvolvimento é a habilidade não só do saber, mas de encontrar cientistas que conseguem entregar um produto que tenha algum tipo de adequação com a necessidade de mercado, que tenham a habilidade de focar no que vai agregar valor para o negócio e não necessariamente no que traz uma satisfação pessoal e intelectual para o cientista" (Gestor 2).

Foi citada, também, a capacidade do cientista em "lidar com o mundo externo e pensar estrategicamente em como proteger as inovações que ele faz" (Gestor 2); e a capacidade de interagir com a equipe da gestora, de forma a aceitar críticas e construir o futuro da empresa

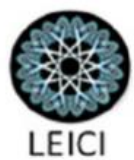


em conjunto, pois "só é possível investir em empreendedores que têm uma cultura de construção e abertura para participação de alguém de fora" (Gestor 3).

O Gestor 4 simplifica a análise sobre o empreendedor quando diz que "gosta de dono com cabeça de investidor". O Gestor explica que privilegia o empreendedor que tem a consciência que um fundo de investimento tem hora para entrar e hora para sair e que, juntamente com o fundo, quer multiplicar o valor da companhia para possivelmente, no futuro, querer vender a sua participação na empresa.

No tocante às características sobre a estrutura e sobre a cultura organizacional, é possível observar que os gestores entrevistados se preocupam menos com a estrutura da empresa e mais com a sua cultura de inovação.

O Gestor 3 explica que, num estágio de estruturação insipiente, visto que as empresas prospectadas são em sua maioria pequenas, a estrutura não é um fator muito chave na avaliação. Por outro lado, a cultura inovadora é observada de forma a verificar se a "metodologia de pesquisa tem objetivos claros de desenvolver aspectos de inovação, e se isso é considerado como uma atividade específica ou se é uma consequência da atividade operacional" (Gestor 1).

\begin{abstract}
"Na questão da metodologia, eu acho que é importante verificar se naquele processo de inovação específico, ou no desenvolvimento de um produto, ou no desenvolvimento de um serviço, ou de um software, se foi feita uma pesquisa do que existe e das rotas tecnológicas. É interessante, por exemplo, em um processo que é o gap analysis, identificar quais são os concorrentes para aquela determinada tecnologia, quais são as características desses concorrentes, o que tem de vantagem, de desvantagem" (Gestor 1).
\end{abstract}

Ainda sobre a cultura, o Gestor 2 ilustra que "a fórmula mágica que é muito difícil de achar é uma cultura organizacional que dá o mesmo valor à qualidade da inovação e ao resultado comercial. Geralmente quando uma das duas ganha mais peso, a outra acaba sendo prejudicada". Além disso, foi colocado pelo Gestor 2 a cultura comercial como sendo importante, pois, segundo ele "a maior parte das empresas inovadoras do mundo bem sucedidas são empresas que trabalham muito para se manter na frente dos demais no ponto de vista da inovação, mas sempre com uma abordagem comercial muito forte".

Em relação à importância do desenvolvimento de pelo menos uma inovação, todos os gestores afirmaram que buscam empresas que tenham desenvolvido pelo menos uma inovação. Os relatos apontam que não necessariamente a empresa deve ter comercializado o produto, porém deve ter uma visão clara de como o produto vai ser levado ao mercado. Nessa esteira, o Gestor 2 afirma que "criar um produto novo, adequar esse produto a um público e achar um canal de distribuição que permita levar esse produto para o público alvo é extremamente complexo".

O Gestor 4 explica que analisa o portfólio de inovações da companhia, pontuando a barreira de entrada à inovação e também a aderência ao mercado. Dentro desse quesito, avalia o estágio de adoção do produto e o diferencial tecnológico dele aos seus concorrentes. Esse testemunho reforça as opiniões anteriores que citam o foco no cliente e a comercialidade do produto como sendo um fator crucial na avaliação dos gestores.

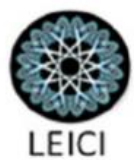


Conforme se pode observar, o lado comercial das inovações é um ponto central na avaliação dos gestores. Assim, não basta ter uma inovação para receber o investimento. A inovação tem que se mostrar comercializável e, principalmente, com barreiras de entradas para novos entrantes.

\subsection{Avaliação do potencial de inovação}

No que tange a avaliação da intensidade tecnológica, todos verificam os dispêndios em P\&D. Nessa esteira, o Gestor 2 explica que, no caso das empresas nascentes, faz todo sentido que elas gastem cinquenta ou sessenta por cento da receita em P\&D.

O Gestor 4 afirma fazer uma avaliação financeira minuciosa, principalmente em relação à otimização de recursos e gastos com $\mathrm{P} \& \mathrm{D}$, marketing e vendas.

Questionados sobre o método de avaliação do potencial de inovação das empresas prospectadas, todos os gestores afirmaram que é importante a empresa ter desenvolvido pelo menos uma inovação. $\mathrm{O}$ Gestor 1 confirmou que analisa se a empresa recebeu prêmios ou apoio para inovar de instituições como FINEP, BNDES, CNPQ, FAPESP, e outros atores relevantes no meio.

Por sua vez, o Gestor 2 confirmou que considera o número de patentes que a empresa depositou e, inclusive, o local no qual essas patentes foram depositadas ou requeridas, como elas foram escritas e por quem.

O Gestor 3, por sua vez, entende que a questão das patentes como forma de avaliar o potencial inovador da empresa é questionável, visto que nem sempre a patente é a melhor forma de proteger determinada propriedade intelectual. Segundo ele, essa questão é relativizada na análise. Para ele, "quem consegue ter patente, é porque conseguiu uma inovação, não necessariamente quem tem uma inovação tem patente".

Em relação à taxa de inovação do setor onde a empresa está inserida, nenhum Gestor mencionou claramente esse indicador. Contudo todos os entrevistados citaram de alguma forma que verificam as tendências de mercado e economia, e os movimentos de inovação do setor no qual a empresa está inserida. Eles afirmaram analisar dados como o histórico do setor, a sua resiliência às mudanças no cenário macroeconômico, seu crescimento e o tamanho do mercado consumidor.

O Gestor 1 indicou que é importante que a empresa esteja informada sobre o que está acontecendo no mundo em relação à tecnologia que ela está desenvolvendo e disse estudar as últimas patentes depositadas em relação a esse tema. Por sua vez, o Gestor 3 confirmou que analisa a tecnologia da empresa, como ela está em termos de desenvolvimento e tendências em relação a outros tipos de tecnologia para aquele determinado tipo de solução. Alem disso,, é feita uma análise de concorrentes, onde são consideradas as tecnologias concorrentes para aquele determinado tipo de problema, e são analisadas, do ponto de vista do cliente, quais são as vantagens e desvantagens de cada uma, e como que a tecnologia em análise se situa em relação às demais.

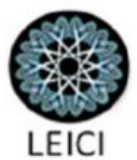


Ainda sobre a questão da avaliação do potencial inovador, o Gestor 3 diz que é importante avaliar as barreiras de entrada para outros entrantes do mercado. Segundo ele, a empresa "tem que ter uma barreira de entrada para outros entrantes do mercado que seja relevante a ponto de que o novo entrante prefira comprar a empresa, a concorrer com ela".

O Gestor 4 coloca a questão do transbordamento tecnológico como importante, pois, segundo ele, se uma empresa está tentando emplacar uma inovação em um mercado e não está sendo bem-sucedida, essa inovação pode ser utilizada em outro setor. Além disso, são analisados a velocidade de adoção de uma nova tecnologia e o potencial de utilização em massa do novo produto.

\subsection{Estímulo à inovação}

No quesito financeiro, todos os entrevistados concordam que os gestores de VC conseguem trazer mais disciplina financeira para as operações da empresa, montando uma estrutura de capital ideal, implementando processos e otimizando a aplicação dos recursos.

O Gestor 3 explica que, além do investimento, a atuação financeira na empresa é através da busca de novos investidores, financiamentos adequados e isenções. O Gestor 1, por sua vez, entende que o objetivo financeiro é justamente organizar a empresa para que o processo de inovação seja destinado a gerar receita e gerar lucro. Ele comenta que aquilo que está sendo desenvolvido seja feito no sentido de gerar produtos e serviços aderentes ao mercado, com custo mais baixo e margem de lucro maior.

Os gestores explicaram que ajudam na gestão através da atração e retenção de talentos para a equipe ou membros destacados para o conselho e até apresentam o empreendedor para potenciais parceiros.

Segundo o Gestor 4, a proposta de valor que é vendida para o empreendedor quando o fundo entra na empresa é: 1) a ajuda financeira; e 2) governança. O Gestor explica que atua nas investidas, primeiramente, através do estabelecimento de um conselho de administração ativo com pessoas experientes na parte financeira e na parte tecnológica.

O Gestor 2 afirma que: "a maior contribuição real que a gente tem é ter escolhido as pessoas certas na frente da empresa". Nesse sentido, o Gestor 3 complementa dizendo que ajuda a atrair e reter talentos para formar o corpo executivo, e a partir daí criar as estruturas e processos e culturas para empresa continuar ou começar a crescer.

O Gestor 1 expõe que desenvolve juntamente com o empreendedor um programa de planejamento estratégico anual que permite selecionar quais produtos serão priorizados e como serão financiados.

O Gestor 3 explica que, na sua opinião, a principal contribuição dada às empresas em "early stage" é a mudança do foco da cabeça do empreendedor. Ele explica que "quando um fundo investidor entra na dinâmica, a questão passa a ser o que é melhor para a empresa nesse momento, e isso faz uma grande diferença em termos de profissionalização". Ele explica que "a partir dessa mentalidade, a empresa ganha força e com ela, qualidade nos produtos e desenvolvimento de novas inovações".

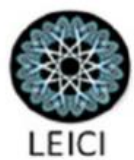


Em relação à rede de contatos, todos os entrevistados concordam que um dos grandes benefícios para a empresa e ter a oportunidade de ter contato com a rede de contatos dos gestores de VC. Contudo, ressaltam que as empresas têm que saber aproveitar essa oportunidade.

\section{Conclusões}

Após o estudo da bibliografia disponível sobre as características das empresas inovadoras, indicadores de inovação e as estratégias de apoio à inovação, foram elencadas as questões essenciais que serviram de guia na abordagem da pesquisa para compreender a opinião dos gestores de fundos de VC acerca da inovação nas empresas apoiadas (FRANCO, 2003). Tais questões guiaram a elaboração do roteiro semiestruturado de entrevista, apoiaram a categorização dos protocolos de transcrição e a exploração das percepções dos entrevistados.

A literatura e os resultados das entrevistas indicam sinergias importantes. O processo de análise em busca de semelhanças entre as percepções dos entrevistados e a literatura, por meio de análise de conteúdo com categorização, à priori, identificou elementos aderentes à formulação teórica das características das empresas inovadoras (FRANCO, 2003; BARDIN, 1977).

No âmbito das características percebidas em empresas, a análise das informações mostrou uma predominância da importância de uma equipe engajada (RIECHE E SANTOS, 2006), incluindo o empreendedor (CUNHA,2005), em práticas inovadoras que permitam, principalmente, transformar a inovação em um produto comercial. Em suma, a qualidade da equipe e do empreendedor é de grande importância na tomada de decisão dos gestores, que, por sua vez, buscam times tecnicamente qualificados para desenvolver inovações que sejam comercializáveis e empreendedores comprometidos com o crescimento da empresa.

No aspecto comercial, notou-se que os gestores avaliam o enfoque que a empresa dá ao priorizar a perspectiva do cliente em seu modelo de negócio. Além de ser um produto vendável, é importante que ele satisfaça uma necessidade específica do cliente e, principalmente, que não seja facilmente copiado (TIDD, BESSANT e PAVIT, 1997; ROTHWELL, 1994). As entrevistas indicaram que barreiras de entrada são observadas durante a análise da inovação da empresa.

$\mathrm{Na}$ dimensão dos indicadores de inovação, percebe-se que é importante, na visão dos entrevistados, o registro da patente da inovação (FURTADO e QUEIROZ, 2007; KORTUM e LERNER, 2000). Além disso, ficou bastante explícita a preocupação dos entrevistados no tocante à reprodução do produto. Os gestores afirmaram avaliar as barreiras de entrada para novos entrantes, demonstrando que é importante que estas sejam altas, impossibilitando que concorrentes possam facilmente copiar a solução inovadora das suas investidas.

A participação de fundos de VC no capital de pequenas e médias empresas é uma fonte de recursos bastante importante, tanto para o crescimento quanto para a sustentabilidade destas empresas. Em que pese à importância do apoio financeiro ao plano de negócios das

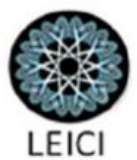


investidas (RAPINI, 2009; ANSELMO e GARCEZ, 2005), ficou nítido que a o grande suporte que é dado pelos gestores de VC é o aperfeiçoamento da gestão e a profissionalização das investidas, que permite à empresa aprimorar a sua forma de gestão, incorporando competências capazes de alavancar o seu crescimento (RIBEIRO, 2005). Na opinião dos entrevistados, a partir dessa mudança sutil, a empresa consegue se estruturar e gerir melhor suas equipes, desenvolver novas inovações e crescer.

Vale comentar que algumas limitações foram identificadas nesse estudo, já que a pesquisa foi restrita aos gestores de $\mathrm{VC}$ que gerem fundos com foco em inovação e apoiados pelo BNDES, e não à totalidade de gestores no mercado. $\mathrm{O}$ método qualitativo adotado não visa à generalização estatística dos resultados. Para pesquisas futuras, sugere-se investigar se os elementos aqui expostos pelos gestores influenciam na avaliação dessas empresas e, em caso positivo, como são precificados. Dessa forma, sugere-se investigar se a metodologia de avaliação de empresas utilizadas por esses gestores incorpora variáveis de natureza qualitativa e subjetiva ao método tradicional do fluxo de caixa descontado.

\section{Bibliografia}

ARVANITIS, S.; STUCKI, T. The impact of venture capital on the persistence of innovation activities of start-ups. Small Business Economics, Abril 2014. 849-870.

BARDIN, L. Análise de Conteúdo. Editora Persona. 1977

BOGLIACINO, F.; LUCCHESE, M. Access to finance for innovation: The role of venture capital and the stock market. IPTS Working Paper on Corporate R\&D and Innovation, 2011.

BURLAMAQUI, L.; PROENÇA, A. Inovação, Recursos e Comprometimento: Em Direção a uma Teoria Estratégica da Firma. Revista Brasileira de Inovação, v. 2, p. 79110 , jan/jun 2003.

CUNHA, N. As práticas gerenciais e suas contribuições para a capacidade de inovação em empresas inovadoras. Universidade de São Paulo. São Paulo. 2005.

DENZIN, N. K; LINCOLN, Y. S. The Sage handbook of qualitative research. Sage. 2011 ENGEL, J. Accelerating Corporate Innovation: Lessons from the Venture Capital Model. Technology Management, p. 36-43, Maio-Junho 2011.

EISENHARDT, K. M. Building theories from case study research. Academy of Management Review, v. 14, n. 4, p. 532-550. 1989.

FRANCO, M. L. P. B. Análise de conteúdo. Brasília: Plano. 2003.

FIATES, J. E. Influência dos Ecossistemas de Empreendedorismo Inovador na Indústria de Venture Capital: Estratégias de Apoio às Empresas Inovadoras. Universidade Federal de Santa Catarina, Programa de Pós Graduação em Engenharia e Gestão do Conhecimento, Tese de Doutorado. Florianópolis. 2014.

FURTADO, A.; QUEIROZ, S. A construção de indicadores de inovação. Informática, v. 25, n. 9, p. 3-7, 2007.

IBGE. Pesquisa de Inovação 2009-2011. IBGE - INSTITUTO BRASILEIRO DE GEOGRAFIA E ESTATÍSTICA. Rio de Janeiro. 2013.
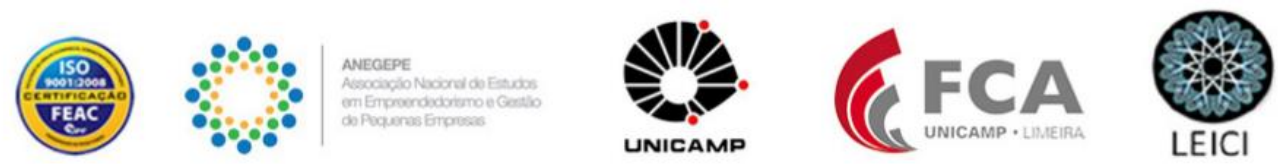
KAPLAN, R. S; NORTON, D. P. Measuring the Strategic Readiness of Intangible Assets. Harvard Business Review, 82(2). https://doi.org/Article (2004)

KORTUM, S.; LERNER, J. Assessing the contribution of venture capital to innovation. The Rand Journal of Economics, 2000. 674-692.

LUNDVALL, B.-A. National Innovation Systems - Analytical Concept And Development Tool. Dinamarca. 2005.

METCALFE, J. S. The Entrepreneur and the Style of Modern Economics. Journal of Evolutionary Economics, v. 14, p. 157-175, 2004.

NEELY, A.; HII, J. The Innovative Capacity of Firms. University of Cambridge. Cambridge. 1999.

OECD. Manual de Oslo: Diretrizes para a Coleta de Interpretação de Dados sobre Inovação. Organização para Cooperação e Desenvolvimento Econômico. Paris. 2004.

PAPACONSTANTINOU, G. Technology and Industrial Performance. The OECD Observer, v. 204, p. 6-10, Fevereiro/ Março 1997.

PAPADAKIS, M.; BOURANTAS, D. The chief executive officer as corporate champion of technological innovation: an empirical investigation. Technology Analysis \& Strategic Management, p. 89-109, Março 1998.

PENROSE, E. The theory of the growth of the firm. Oxford: Basil Blackwell, 1959.

REMENY, Dan; WILLIAM, Brian; MONEY, Arthur, SWARTZ, Ethné. Doing Research in Business and Management. London: Sage. 1998

RIBEIRO, L. O Modelo Brasileiro de Private Equity e Venture Capital. São Paulo. 2005. RIECHE, F.; SANTOS, L. Investimentos em Pequenas e Médias Empresas com Elevado Potencial de Crescimento - Critérios de Seleção dos Capitalistas de Risco. Revista do BNDES, Rio de Janeiro, v. 13, n. 26, p. 89-114, dezembro 2006.

ROTHWELL, R. Towards the Fifthy-generation Innovation Process. International Marketing Review, p. 7-31, 1994.

SAHLMAN, W. The Structure and Governance of Venture-Capital Organizations. Journal of Financial Economics, v. 27, n. 2, p. 473-521, 1990.

SANTOS, R.; NETO, M.; MOURA, G. Gestores de empresas inovadoras: características e singularidades. XIII Semead Seminários em Administração. São Paulo. 2010.

SEBRAE. MPEs de Base Tecnológica: conceituação, formas de financiamento e análise de casos brasileiros. Serviço de Apoio às Micro e Pequenas Empresas. São Paulo. 2001.

TAROZZI, M. O que é grounded theory? Editora Vozes. 2008

TEECE, D.; PISANO, G.; SHUEN, A. Dynamic capabilities and strategic management. Strategic Management Journal, 1997.

TIDD, J.; BESSANT, J.; PAVIT, K. Managing Innovation: integrating technplogical, market and organizational change. London: John Wiley \& Sons Ltd, 1997. 